\title{
Bone Fibrosarcoma
}

National Cancer Institute

\section{Source}

National Cancer Institute. Bone Fibrosarcoma. NCI Thesaurus. Code C6604.

A usually aggressive malignant neoplasm arising from the bone. It is characterized by the presence of spindle-shaped fibroblasts and collagenous stroma formation in a herring bone growth pattern. 